\title{
Neural activity differs between explicit and implicit learning of artificial grammar strings: An fMRI study
}

\author{
CAROL A. SEGER \\ Colorado State University, Fort Collins, Colorado \\ and \\ VIVEK PRABHAKARAN, RUSSELL A. POLDRACK, and JOHN D. E. GABRIELI \\ Stanford University, Stanford, Califormia
}

\begin{abstract}
Functional magnetic resonance imaging was used to investigate the neural areas underlying retrieval of implicit and explicit knowledge about letter strings. Participants studied strings formed according to an artificial grammar, then performed implicit-learning-based judgments (judging the grammatical status of the string) or explicit-learning-based judgments (recognition) on novel grammatical strings. In comparison with a baseline task, recognition and grammatical judgments led to different patterns of neural activation: Recognition activated the right frontal cortex, whereas grammatical judgment activated the left frontal cortex. Recognition led to higher activity in the precuneus and medial occipital cortex, whereas grammatical judgments led to suppression of activity in the precuneus and activation in the lateral occipital cortex. When the surface structure of the strings was changed, grammatical judgments led to bilateral frontal activity and bilateral but left-lateralized activity in the occipital and parietal lobes. These results provide further evidence for a dissociation between the neural bases of implicit and explicit learning.
\end{abstract}

An influential neuropsychological finding in the field of human memory has been the dissociation of implicit from explicit memory. Explicit, or declarative, memory is memory for facts and events; it is dependent on the hippocampal and diencephalic brain systems (Cohen, Poldrack, \& Eichenbaum, 1997; Squire, 1994). Implicit memory is a heterogeneous set of phenomena that have in common that they are preserved in patients with global amnesia and thus are independent of the hippocampaldiencephalic brain systems. These phenomena include motor skills and sequencing (Corkin, 1968; Nissen \& Bullemer, 1987), perceptual and conceptual priming (Graf, Squire, \& Mandler, 1984; Warrington \& Weiskrantz, 1970), and implicit learning of patterns, such as artificial grammar learning (Knowlton, Ramus, \& Squire, 1992; A. S. Reber, 1967).

In the artificial-grammar-learning task (A. S. Reber, 1967, 1989), participants study letter strings generated using an artificial grammar (see Figure 1) without being

This research was supported by a National Research Service Award from the National Institute of Mental Health to C.A.S. We thank John Desmond, Margaret Zhao, Gary Glover, Chandan Vaidya, Christina Fales, Anthony Wagner, and Jim Brewer for assistance during design and data analysis. R.A.P. is now at the Massachusetts General Hospital Nuclear Magnetic Resonance Center. Correspondence concerning this article should be addressed to C. A. Seger, Department of Psychology, Colorado State University, Fort Collins, CO 80523 (e-mail: seger@) lamar.colostate.edu). informed of the structured nature of the strings. Participants are then told of the existence of the underlying grammar and are asked to judge novel strings as to whether they are grammatical or not (i.e., whether the string follows the same rules as the strings in the study task). Participants typically report relying on their intuition or "gut feelings" in making these judgments. Grammaticality judgments are influenced by previous experience with rulegenerated stimuli and thus reflect learning; this learning is implicit in that participants are not aware of the specific rules underlying the stimuli (Seger, 1994).

The artificial-grammar-learning task is well suited to direct comparison with explicit memory tasks, such as recognition. Participants can be shown the same sorts of stimuli (letter strings) and can indicate their judgments via the same sort of responses (keypresses indicating "yes" or "no") in both recognition and grammatical judgment conditions. What differs is the memory resources drawn on to make each judgment. For recognition tasks, participants attempt to recall a specific episodic memory of the stimulus in order to verify that the stimulus was previously experienced. For grammatical judgments, participants make a decision on the basis of feelings of correctness or familiarity. Grammatical judgment has been shown to be independent of the hippocampal-diencephalic memory systems in research performed with patients with global amnesia. Knowlton and Squire (1994, 1996; Knowlton et al., 1992) found that amnesic patients exhibit normal performance on grammatical judgments of strings but 


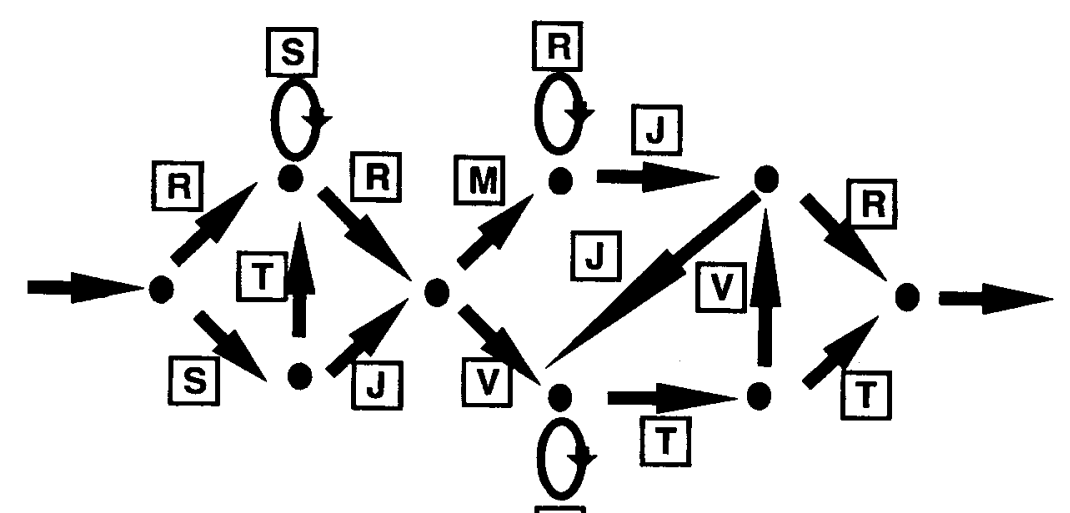

M.

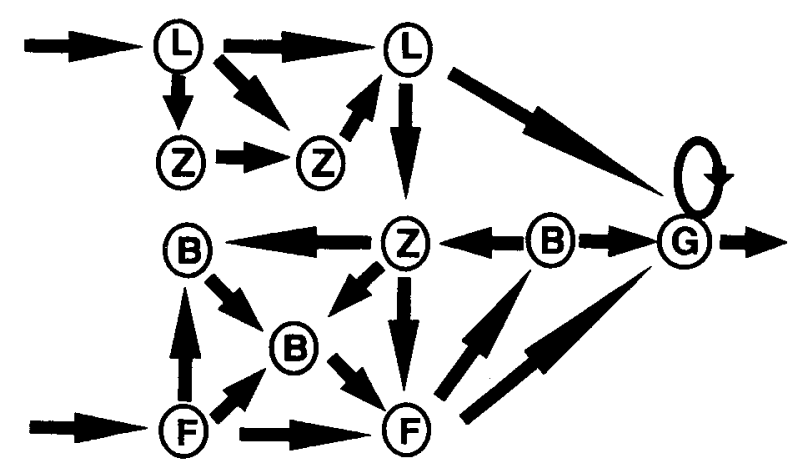

Figure 1. Artificial grammars used to generate stimuli for the implicit (top) and explicit (bottom) conditions. Strings are formed by starting with an arrow leading in from the left and ending when the arrow leading out to the right is reached. For example, the top grammar can produce RSRMRRJR, STSRVMMTT, RRVTVJTT, or SJMJR, and the bottom grammar can produce FFBG, LZLZFGG, FBBFGGG, or LLGGGG.

were impaired when asked to make recognition judgments for new versus old strings. In addition, patients with Huntington's disease, who have damage to the basal ganglia, exhibit normal artificial grammar learning (Knowlton et al., 1996). Thus, neuropsychological research indicates that artificial grammar learning is independent of both the hippocampal and the striatal learning systems but does not indicate what neural systems may subserve this form of learning.

Fletcher, Dolan, and colleagues (Dolan \& Fletcher, 1999; Fletcher, Buchel, Josephs, Friston, \& Dolan, 1999) have published the only previous functional imaging study of artificial grammar learning. They used an unusual form of the artificial-grammar-learning task: Instead of a study session followed by a classification session, participants learned to classify via feedback. Participants viewed a string, decided whether it was grammatical or not, and then were told the actual grammatical status of the string. Within blocks, strings were repeated; the au- thors argued that participants in this situation would make grammaticality judgments on the basis of recognition. Between blocks, strings were changed, so that at the beginning of each block the strings were novel; the authors argued that, in this situation, participants would make grammatical judgments on the basis of abstracted patterns or rules. They examined activity in comparison with a sensorimotor baseline task (viewing rows of the same letter and pressing either the left or the right key) across the course of the experiment (Fletcher et al., 1999). The right prefrontal cortex was active early in the experiment, when judgments were presumably made on the basis of recognition. The left prefrontal cortex was active across the beginnings of blocks, when judgments were presumably made on the basis of abstracted information. Thus, the authors found differences in neural activity between grammatical judgments made on the basis of recognition and those made on the basis of abstraction. However, explicit and implicit judgments were confounded 
with level of experience: Early blocks were associated with recognition, and later blocks with pattern processing. Furthermore, all the decisions were grammatical judgment decisions, and participants were not instructed to use recognition as a basis for their decisions. It is uncertain, therefore, which activations were related to implicit learning and which to explicit learning.

Behavioral research has indicated that artificial grammar learning is abstract, in the sense that the information learned is not strictly linked to the surface features of stimuli. Amnesic participants, as well as normal participants, can transfer grammar knowledge to strings in which the underlying grammar is the same but the letters used to instantiate them have been changed (Gomez \& Schvaneveldt, 1994; Knowlton \& Squire, 1996; Mathews et al., 1989; A. S. Reber, 1969). Furthermore, studies show transfer to novel letter-like symbols (Altmann, Dienes, \& Goode, 1995; Chan, cited in Berry \& Dienes, 1993) and across sensory modalities (Altmann et al., 1995; Manza \& Reber, 1997). There are two main theories that explain how implicit knowledge can be transferred. One theory is that participants learn abstract information, such as rules, which are applied directly to the transfer strings in the same manner as to the same-letter strings. Another theory argues that participants form a mapping between letter sets that allows them to make classifications (Dienes, Altmann, \& Gao, 1999). Transfer performance is reliably greater than chance but is only approximately $70 \%$ as great as same-letter performance (Altmann et al., 1995; Manza \& Reber, 1997), indicating a cost in transferring letter sets.

The present study used a study-test procedure that was similar to that employed with normal and amnesic patients in behavioral studies: Participants first observed a set of grammatical strings, then were tested on what they learned about the strings while functional images were acquired. Furthermore, the study design separated grammatical and recognition judgments: One group of participants (the implicit group) made grammatical judgments, and a different group (the explicit group) made recognition judgments. This between-subjects design was adopted in order to avoid contamination of each task by the other; pilot testing indicated that participants often adopted the same decision strategy for both recognition and grammatical judgment, even when they were instructed to perform the tasks differently. Implicit participants performed three tests: a grammatical judgment test (the judge test), a test examining differences in processing of grammatical and nongrammatical items (the $G-N G$ test), and a transfer grammatical judgment test in which the strings were presented in a different letter set (the transfer test). Explicit participants performed one test, in which they made recognition decisions about grammatical new and old strings (the recognition test). Each test was structured as alternating blocks of judgments and baseline tasks, with the exception of the G-NG test, in which participants made grammatical judgments throughout and the grammatical nature of the strings was alternated.

We predicted two main areas of activation. First, there would be areas of the frontal lobes active in making decisions, owing to the roles of the frontal lobes in working memory and higher level thought. In particular, we predicted that the recognition task would activate right frontal areas, as in other recognition tasks (Buckner, Koutstaal, Schacter, Dale, et al., 1998; Buckner, Koutstaal, Schacter, Wagner, \& Rosen, 1998; Fletcher, Shallice, Frith, Frackowiak, \& Dolan, 1998; Rugg et al., 1998; Schacter, Buckner, Koutstaal, Dale, \& Rosen, 1997; Squire et al., 1992; Tulving, Kapur, Craik, Moscovitch, \& Houle, 1994; Wagner, Desmond, Glover, \& Gabrieli, 1997), and judgment would rely more heavily on categorical processes in the left hemisphere (Fletcher et al., 1999; Goldberg \& Costa, 1981; Seger et al., 2000). Second, we predicted that there would be activity in the occipital lobes, owing to enhanced attention and feature analysis of stimuli during implicit and explicit judgments in comparison with the baseline (P. J. Reber, Stark, \& Squire, 1998a, 1998b).

\section{METHOD}

\section{Participants}

Fourteen right-handed members of the Stanford community participated. Seven participated in the implicit condition ( 4 men and 3 women), and 7 (6 men and 1 woman) in the explicit condition. Each participant provided written consent, using a form approved by the Institutional Review Board at Stanford University.

\section{Materials}

Letter strings used as stimuli were formed according to the artificial grammars shown in Figure 1. Grammar 1, used in the implicit condition, is an extension of a grammar created by Mathews et al. (1989), which was in turn an extension of a grammar developed by A. S. Reber (1967). Grammar 2, used in the explicit condition, was developed by Gomez (1997), as an extension of the grammar used by A. S. Reber (1969). Pilot testing indicated that both grammars were approximately equally easy to learn in grammatical judgment and recognition tasks. Grammar 1 can produce a total of 204 grammatical strings of length 10 or shorter; of these, 30 were randomly allocated to the learning phase, 96 to the judge and transfer tests and 48 to the G-NG test. The learning list of 30 randomly ordered strings was presented four times to the participants in the learning phase, for a total of 120 study trials.

For G-NG, nongrammatical strings were formed by taking each of the 204 grammatical strings and changing one or two letters. Chunk strength, a measure of overlap of the bigrams and trigrams present in the string with the strings in the learning set (Knowlton \& Squire, 1996), was calculated for both grammatical and nongrammatical strings as the sum of frequencies of occurrence in the learning list for each bigram and trigram in the string divided by the total number of bigrams and trigrams in that length string (e.g., there is a total of seven, four bigrams and three trigrams, in a string five letters in length). The 48 nongrammatical strings with the lowest chunk strength (range, 2.2-5.2; 13 strings had a single error, and 39 strings had two errors) and the 48 grammatical strings with the highest chunk strength (range, 7.3-10.4) were chosen as stimuli. The goal was to have the nongrammatical and grammatical sets be as different as possible, within the constraints of a typical artificial- 
grammar-learning study, in order to maximize the chance of finding neural activity differences between the two stimulus types. The final test list was made by alternating blocks of 12 grammatical strings with 12 nongrammatical strings, for a total of eight blocks, four of each type. Strings were randomly ordered within the blocks.

For the judge and transfer tests, a list was formed of 96 different grammatical strings. Judge and $\mathrm{G}-\mathrm{NG}$ test strings were presented in the same letter set as the learning list: S, R, T, J, M, and V. In the transfer test, the strings were presented in the second letter set: letters $S$, $R, T, J, M$, and V were changed to $X, P, D, K, N$, and C, respectively. Grammar 2 can produce a total of 194 grammatical strings of length 10 or shorter; of these, 15 were randomly allocated to the learning phase, and 48 to the testing phase. The learning list consisted of the 15 strings ordered randomly; the list was repeated eight times, for a total of 120 trials. The number of different strings was changed from 30 strings repeated four times to 15 strings repeated eight times for the recognition test, because pilot testing found very low levels of recognition ability in the former condition. For the recognition test, a randomly ordered list was formed of 48 novel grammatical strings and 48 repeated grammatical strings. Each learning list string appeared three times as a repeated string in the testing list; 3 strings appeared four times. The average chunk strength of the 48 novel strings was 6.6 , and the average chunk strength of the 48 repeated strings was 6.3 ; thus, chunk strength did not differ for novel and repeated strings.

\section{Procedure}

The stimuli were generated from a computer and back-projected onto a screen located above the participant's neck via a magnetcompatible projector. Visual images were viewed from a mirror mounted above the participant's head. The participants were placed in the scanner and began the experiment by viewing the learning strings while structural images were acquired. The participants were instructed to pay full attention to the strings and to attempt to impress them on their memory, but not to engage in strategies such as counting letters. Implicit condition participants viewed the Grammar 1 learning list, and explicit participants viewed the Grammar 2 learning list; the 120 strings were presented for $2 \mathrm{sec}$ each.

Implicit participants performed three tests, in this order: judge, $\mathrm{G}-\mathrm{NG}$, and transfer. The participants were instructed that the strings in the first part were constructed according to complex rules; they were to judge the new strings as to whether they followed the rules or not. The participants were instructed to used their intuition or "gut feelings" in making their judgments. In the judge condition, the participants were presented with the 96 grammatical strings. The participants alternated the task that they performed across four cycles, so that they performed the grammatical judgment task for 12 strings, then the baseline task for 12 strings. For the grammatical judgment task, the participants were asked to press the response key if the string followed the same rules as the strings studied in the learning portion of the experiment. For baseline trials, the participants were asked to press the response key if there was a TT in the string. The participants were cued at the beginning of every halfcycle as to which judgment to perform on the successive strings; the cue took the same time as one stimulus presentation. The participants viewed each string for $3 \mathrm{sec}$, and made their response during that interval; the next string was presented immediately after. The participants were not given feedback about their responses. In the G-NG test, the participants performed grammatical judgment throughout; the grammatical status of strings changed with each half-cycle, so that the participants viewed 13 grammatical strings, then 13 nongrammatical strings. The participants were not cued as to the grammatical status of the strings. The transfer test was the same as the judge test, except that the strings were presented using the second letter set and the perceptual baseline task was to decide whether there was a DD in the string. The participants were warned of the letter set change and were asked to continue making their grammaticality judgments in the same way as in the judge test.

Explicit participants performed the recognition test. The participants alternated making recognition judgments (was this string one of the strings that you just studied in the preceding learning task?) with the baseline task (is there a GG in the string?) across eight cycles of 12 strings presented for $3 \mathrm{sec}$ each. The participants were instructed to make their recognition judgments on the basis of an actual event memory of seeing the string, rather than on the basis of string familiarity.

\section{Functional Magnetic Resonance Imaging Methods}

Imaging was performed with a $1.5 \mathrm{~T}$ whole-body magnetic resonance imaging scanner (GE Medical Systems Signa). A prototype receive-only whole-head coil was used for signal reception. A bite bar formed with each participant's dental impression was used to minimize head motion. Sixteen contiguous 4-mm-thick slices were acquired parallel to the anterior commisure (AC)-posterior commisure (PC) plane, extending from $18 \mathrm{~mm}$ below to $46 \mathrm{~mm}$ above the AC-PC plane. Thus, the inferior cerebellum, the anterior inferior temporal lobes, and the superior frontal and parietal areas were not sampled. T1-weighted flow-compensated spin-warp anatomy images were acquired for each of the slices imaged in the functional scans. A T2*-sensitive gradient echo three-dimensional spiral pulse sequence was used for functional imaging with parameters of TE = $40 \mathrm{msec}, \mathrm{TR}=1,080 \mathrm{msec}$, flip angle $=22,4$ spiral interleaves, and inplane resolution $=2.35 \times 2.35 \mathrm{~mm}$.

Functional magentic resonance imaging (fMRI) data were analyzed for task-related activation, using the general linear model and the theory of Gaussian fields. Functional images were motion corrected, using an automated registration algorithm (AIR 3.0; Woods, Cherry, \& Mazziota, 1992). Images were normalized to a standard space (Talairach \& Tournoux, 1988), using an eight-parameter linear transformation implemented in SPM96 (Wellcome Department of Cognitive Neurology, London, U.K.). Normalized images were smoothed, using a 6.0-mm Gaussian kernel in SPM96. Effects of condition were estimated according to the general linear model at each voxel (Friston, Holmes, et al., 1995), using the fMRI statistics program in SPM96, with global signal intensity and low-frequency components as confounding covariates. Linear contrasts were used to test hypotheses about regionally specific effects, forming a statistical parametric map of voxel values for each contrast. These maps were transformed to the unit normal distribution and thresholded at $p=.001$ (uncorrected). Distributional approximations from the theory of Gaussian fields were used to characterize the statistical significance of activation maps in terms of the probability that an observed cluster size could have occurred by chance across the entire imaged volume at $p=.05$ (Friston, Frith, Turner, \& Frackowiak, 1995).

\section{RESULTS}

\section{Behavioral Performance}

In the $\mathrm{G}-\mathrm{NG}$ test, in which subjects made grammaticality decisions about grammatical and nongrammatical strings, participants correctly classified $58 \%(S D=4.1 \%)$ of the strings. This level of performance is significantly above what would be expected by chance $[t(6)=5.2, p<$ .005 , one-tailed] and is comparable with that found in previous artificial-grammar-learning experiments (e.g., Knowlton \& Squire, 1996; Seger, 1998). The hit rate was $60 \%$ in the grammatical string half-cycles, and the false 
alarm rate was $45 \%$ in the nongrammatical string halfcycles.

In the judge and transfer tests, only grammatical strings were presented. The participants judged $63 \%(S D=$ $8.1 \%$ ) of the strings as grammatical in the same-letter judgment condition ( 2 participants' behavioral data were lost) and 59\% (SD $=14.8 \%)$ in the transfer condition. Behavioral data for 3 of the explicit participants on the recognition test was lost owing to technical problems; the remaining 4 participants correctly indicated whether the string was novel or repeated for $62 \%$ of the strings $(S D=$ $10.1 \%)$, which was significantly above chance $[t(3)=$ $2.38, p<.05$, one-tailed].

\section{Imaging Results}

Judge scan. Three areas were more active during grammatical judgment than during the baseline test: the left dorsolateral prefrontal and the left and right occipi-

Table 1

Areas of Activation

\begin{tabular}{|c|c|c|c|c|c|c|}
\hline Region & $k$ & $Z$ & BA & $x$ & $y$ & $z$ \\
\hline \multicolumn{7}{|l|}{ Judge activations (grammatical judgment $>$ baseline) } \\
\hline \multirow[t]{3}{*}{ Right middle occipital gyrus } & 1,189 & 5.58 & 19 & 38 & -90 & 8 \\
\hline & & & 19 & 30 & -88 & 24 \\
\hline & & & 18 & 26 & -96 & 12 \\
\hline \multirow{3}{*}{ Left middle occipital gyrus } & 880 & 5.26 & 18 & -32 & -96 & 4 \\
\hline & & & 18 & -10 & -98 & 4 \\
\hline & & & 19 & -22 & -98 & 12 \\
\hline \multirow[t]{3}{*}{ Left inferior and middle frontal gyri } & 987 & 4.15 & 45 & -50 & 36 & 16 \\
\hline & & & 47 & -34 & 26 & 0 \\
\hline & & & 10 & -38 & 64 & 8 \\
\hline \multicolumn{7}{|c|}{ Judge deactivations (baseline > grammatical judgment) } \\
\hline \multirow[t]{3}{*}{ Right superior and middle temporal gyri } & 715 & 5.38 & 22 & 66 & -48 & 16 \\
\hline & & & 22 & 50 & -52 & 20 \\
\hline & & & 39 & 64 & -58 & 12 \\
\hline \multirow[t]{3}{*}{ Bilateral precuneus, cuneus, and cingulate } & 1,397 & 4.64 & 23 & 0 & -10 & 32 \\
\hline & & & 18 & -2 & -82 & 24 \\
\hline & & & 7 & -4 & -40 & 44 \\
\hline \multicolumn{7}{|c|}{ Transfer activations (grammatical judgment $>$ baseline, with different letter set) } \\
\hline \multirow[t]{3}{*}{ Left middle and superior occipital gyri } & 1,801 & 5.14 & 19 & -28 & -92 & 28 \\
\hline & & & 19 & -32 & -72 & 32 \\
\hline & & & 19 & -32 & -92 & 16 \\
\hline \multirow{3}{*}{$\begin{array}{l}\text { Right middle and superior occipital gyri and } \\
\text { right superior parietal lobule }\end{array}$} & 789 & 4.32 & 19 & 30 & -70 & 36 \\
\hline & & & 7 & 34 & -62 & 44 \\
\hline & & & 19 & 32 & -88 & 24 \\
\hline \multirow{3}{*}{$\begin{array}{l}\text { Left inferior parietal lobule and } \\
\text { left inferior frontal gyrus }\end{array}$} & 1,630 & 4.29 & 40 & -26 & -44 & 44 \\
\hline & & & 40 & -48 & -24 & 36 \\
\hline & & & 44 & -46 & 8 & 16 \\
\hline \multirow[t]{3}{*}{ Right inferior frontal gyrus, insula } & 874 & 4.93 & 45 & 50 & 16 & 4 \\
\hline & & & 47 & 48 & 26 & 0 \\
\hline & & & & 32 & -20 & -4 \\
\hline \multicolumn{7}{|c|}{ Transfer deactivations (baseline > grammatical judgment, with different letter set) } \\
\hline \multirow[t]{3}{*}{ Bilateral medial frontal and frontal pole } & 1,691 & 4.85 & 10 & -8 & 62 & 20 \\
\hline & & & 11 & 2 & 64 & -16 \\
\hline & & & 11 & 0 & 62 & -24 \\
\hline \multicolumn{7}{|l|}{ Recognition activations (recognition $>$ baseline) } \\
\hline \multirow{3}{*}{$\begin{array}{l}\text { Bilateral lingual gyri, cuneus, precuneus and } \\
\text { right occipital and superior parietal lobule }\end{array}$} & 1,434 & 4.24 & 18 & 4 & -80 & 26 \\
\hline & & & 19 & 32 & -76 & 28 \\
\hline & & & 18 & 2 & -76 & 4 \\
\hline \multirow[t]{3}{*}{ Right inferior and middle frontal gyri } & 652 & 4.52 & 46 & 42 & 48 & 8 \\
\hline & & & 45 & 54 & 36 & 4 \\
\hline & & & 45 & 52 & 24 & 8 \\
\hline \multicolumn{7}{|l|}{ Recognition deactivations (baseline $>$ recognition) } \\
\hline \multirow[t]{3}{*}{ Left insula } & 876 & 5.2 & & -44 & -20 & 0 \\
\hline & & & & -58 & -4 & 0 \\
\hline & & & & -56 & 4 & 0 \\
\hline \multirow{3}{*}{$\begin{array}{l}\text { Left middle and superior temporal gyri and } \\
\text { left inferior parietal lobule }\end{array}$} & 764 & 4.94 & 39 & -58 & -62 & 16 \\
\hline & & & 22 & -70 & -44 & 16 \\
\hline & & & 40 & -60 & -54 & 40 \\
\hline Bilateral medial frontal and frontal pole & 932 & 4.92 & 10 & -10 & 64 & 16 \\
\hline & & & 10 & 10 & 56 & -8 \\
\hline & & & 24,32 & 0 & 38 & -4 \\
\hline
\end{tabular}

Note-Activation clusters met a height threshold of $p<.05$ and a corrected spatial extent threshold of $p<$ .05 . Two local maximum locations are given for each cluster in addition to the global maximum. $k$, number of voxels in cluster. $Z, z$ score of voxel with maximum activation. BA, Brodmann's area. $x, y, z$, Talairach coordinates of the voxel. 


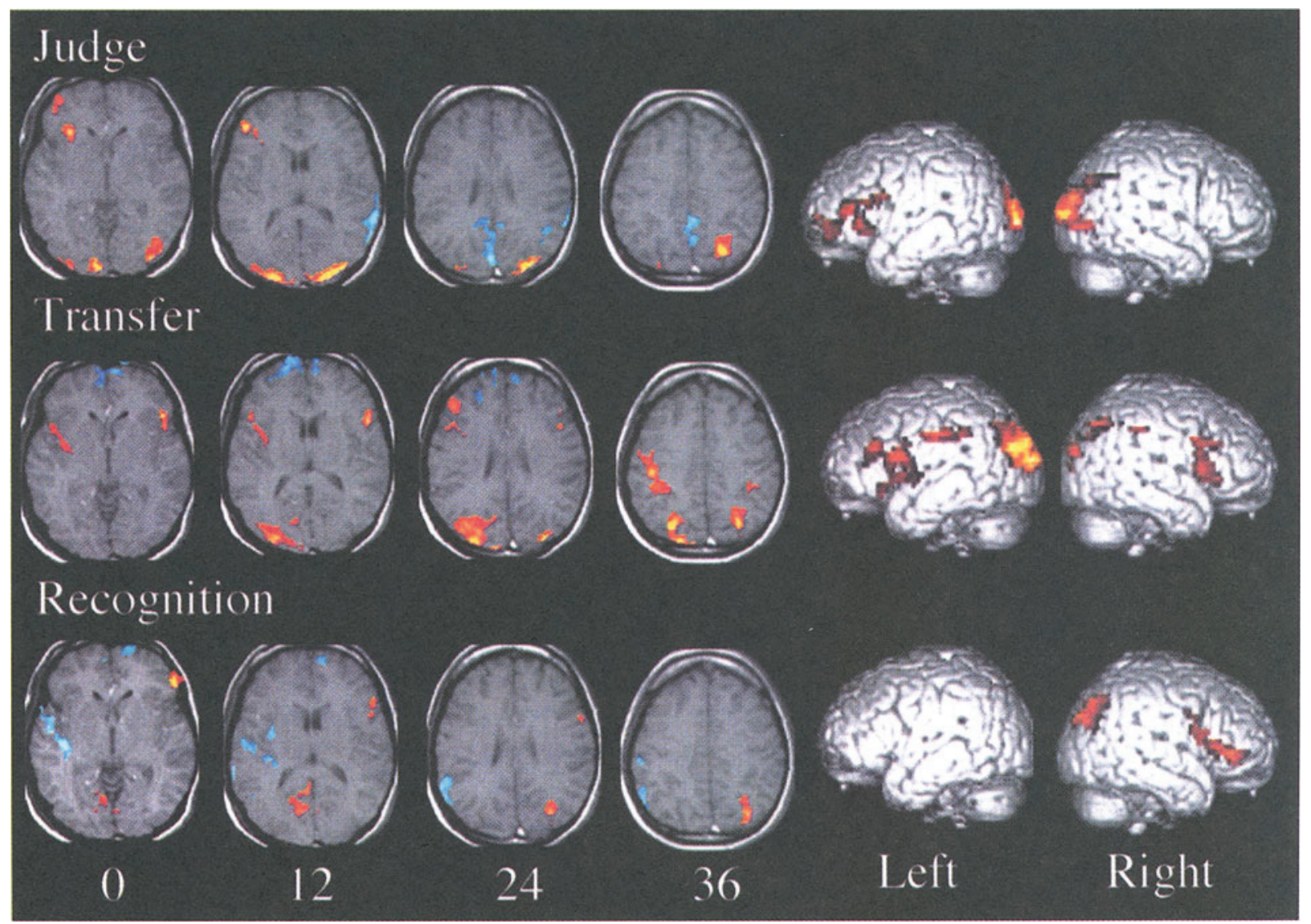

Figure 2. Brain activations across the three conditions. Left panel: averaged activations and deactivations across participants, overlaid on axial MRI images of a typical participant. Slices at $z=0,12,24$, and 36. Red-yellow spectrum: activated areas (more active in performing judgments than in baseline). Blue spectrum: deactivated areas (more active in baseline than in judgments). Right panel: averaged activation rendered on a standardized brain model of the left and right hemispheres.

toparietal cortexes (Table 1). The left frontal activation extended from the inferior frontal gyrus to anterior portions of the middle frontal gyrus (Figure 2). The occipital lobe activations were comparable in both hemispheres: Lateral portions were active (BA 18, 19), extending superiorly to the borders of the superior parietal lobule (BA 7). Two areas showed a deactivation in the grammatical judgment test with respect to the baseline test: an area encompassing the right superior and middle temporal gyri and an area encompassing the bilateral cuneus, precuneus, and posterior cingulate.

G-NG scan. No areas showed significantly different activation to grammatical than to nongrammatical strings.

Transfer. Performing grammatical judgments to strings in the second letter set led to activation higher than baseline in four clusters, shown in Table 1 . The areas activated included the inferior frontal lobes bilaterally and the occipital and parietal lobes bilaterally. In both hemispheres, the frontal lobe activations were in the inferior frontal gyri (BA 44, 45, 47) and did not extend anteriorly to the middle frontal gyri (BA 9, 10). The occipital lobe activations were lateral (BA 18, 19), with some tendency to be stronger on the left. Activation extended into the inferior and superior parietal lobules (BA 7, 40), bilater- ally. The frontal pole and medial frontal areas were deactivated in the transfer task.

Recognition. The occipital lobes and right frontal lobe were significantly more active when performing recognition than in baseline, as is shown in Table 1 . The right frontal lobe activation was centered in the inferior frontal gyrus. The occipital activation was bilateral and medial, extending from the lingual gyri superiorly to the cuneus and precuneus. This activation cluster also included a right lateral occipital activation (BA 19), which extended to the superior parietal lobule (BA 7). Three areas were deactivated during recognition, including the bilateral frontal pole and medial frontal areas, the left superior and middle temporal gyri, and the left insula. The temporal deactivation extended posteriorly to the inferior parietal lobule (BA 40).

\section{DISCUSSION}

Several dissociations were apparent between the brain activations associated with grammatical judgment and recognition. Recognition activated the right frontal areas, whereas grammatical judgment activated the left frontal areas. Recognition activated medial portions of the occip- 
ital lobes, whereas judgment activated lateral portions. Thus, judgments based on explicit learning (right frontal and medial occipital) were subserved by different neural networks than were judgments based on implicit learning (left frontal and lateral occipital).

Differences were also found between grammatical judgments to same-letter strings (the judge condition) and grammatical judgments to strings presented in a novel letter set (the transfer condition). Transferring from sameletter-set to different-letter-set strings led to recruitment of right frontal areas to join the left frontal activity and to greater activity in parietal areas, bilaterally. Occipital activation remained lateral but was left lateralized after transfer. Thus, transfer led to recruitment of additional neural systems (right frontal and bilateral parietal) to join the neural network active in same-letter grammatical judgment (left frontal and lateral occipital). This pattern of brain activation is consistent with theories that state that transfer to a novel letter set requires additional cognitive processing that augments, but does not replace, the cognitive processing used for same-letter grammatical judgments.

Judge, transfer, and recognition tasks all showed different patterns of involvement of the frontal lobes. Activity in the recognition condition was right lateralized, activity in the judge condition was left lateralized, and activity in the transfer condition was bilateral. The right frontal activation found in recognition has been associated with explicit memory processing in other imaging studies (Buckner, Koutstaal, Schacter, Wagner, \& Rosen, 1998; Nyberg, Cabeza, \& Tulving, 1996). It is uncertain what mental processes are subserved by this right frontal activation: Activity has been associated with successful retrieval (Rugg, Fletcher, Frith, Frackowiak, \& Dolan, 1996), attempting to retrieve regardless of success (Buckner, Koutstaal, Schacter, Dale, et al., 1998; Henson, Rugg, Shallice, Josephs, \& Dolan, 1999; Schacter et al., 1997; Wagner et al., 1997), reflective demands (Nolde, Johnson, \& Raye, 1998), and monitoring subsequent to retrieval (MacLeod, Buckner, Miezin, Petersen, \& Raichle, 1998; Rugg et al., 1998).

The left frontal involvement in judge tasks is consistent with previous artificial grammar research (Fletcher et al., 1999). The left frontal lobes have been previously associated with abstraction: Seger et al. (2000) found that successful and unsuccessful concept learners differed only in left prefrontal activation, so that this area was active only for successful learners. When participants transferred to strings presented in a different letter set, frontal activity became bilateral. Recruitment of the right frontal area could be due to the greater difficulty of the transfer task or, possibly, to the novelty of the new letter strings (Bradshaw \& Nettleton, 1983).

There was a dissociation in occipital lobe activation between the recognition task, which activated the medial occipital lobe bilaterally, including the lingual gyrus and cuneus, and the judge and the transfer tasks, which activated lateral portions of the occipital lobe. It is not cer- tain what aspects of stimulus processing are subserved by these medial and lateral areas, but other experiments investigating letter string processing have found similar dissociations. Lateral inferior occipital and fusiform gyri activity has been found to be greater for letter strings than for the nonletter stimuli, such as textures or lines (Puce, Allison, Asgari, Gore, \& McCarthy, 1996; Uchida et al., 1999), or than fixation (Petersen, Fox, Snyder, \& Raichle, 1990). Medial occipital activity has been found to be greater for words and pseudowords than for consonant strings or false font strings (Petersen et al., 1990; but see Price et al., 1994) and greater for words than for pronounceable nonwords (Pugh et al., 1996). It is unclear why recognition should activate areas associated with word processing, whereas grammatical judgment should activate areas associated with letter string processing. However, these results are consistent with findings that explicit and implicit memory processes can have differential effects on occipital lobe activity. P. J. Reber et al. (1998a, 1998b) found that early visual-processing areas (BA 17, 18) were less active to concept members than to nonmembers in a concept membership judgment test but were more active to the concept exemplars in a recognition test.

Activity extended from the occipital lobes to inferior portions of the superior parietal lobule in all three tests. However, this activity was noticeably stronger and more widespread in the transfer test, extending bilaterally to the inferior and superior parietal lobules (BA 40,7). Dienes et al. (1999) argue that letter set transfer in the artificial grammar task involves forming a mapping from the original letter set to the transfer letter set. In this light, it is interesting to note that Wharton et al. (1999) found left parietal activity to be the main neural correlate of analogical mapping. Behavioral research indicates that the mapping process in artificial grammar learning may be implicit, in that participants are not able to consistently verbalize the mapping between letter sets (Manza \& Reber, 1997).

The medial occipital activation in the recognition test extended superiorly to the precuneus. Previous research has often found precuneus activity in recognition tasks. It is still unclear whether this activity reflects visual processing related to explicit memory (Fletcher et al., 1996) or whether the activity is modality independent (Krause et al., 1999). The present study supports the theories that state that precuneus activity is associated with some aspect of explicit, as opposed to implicit, memory processing. Precuneus activity was not found in the judge or transfer conditions; on the contrary, a more superior portion of the precuneus was deactivated in the judge condition.

Several areas were less active during judgments than during the baseline task. Owing to the relatively simple nature of the baseline task, it is reasonable to interpret these activations as areas that were deactivated during the judgments. The superior and middle temporal gyri were deactivated on the right in the judge condition and on the 
left in the recognition condition. Deactivation in these areas, which are related to audition, may reflect a suppression of auditory attention during a demanding visual task (Shulman, Corbetta, et al., 1997). Bilateral medial frontal areas and the frontal pole were deactivated in the transfer and recognition conditions. The bilateral frontal pole and medial frontal cortices commonly show lessened activation in more difficult cognitive tasks, relative to baseline tasks. These deactivations may reflect attention or extraneous thought processes during the relatively unconstrained baseline task (Shulman, Fiez, et al., 1997).

In the G-NG scan, the grammatical status of strings was manipulated while the participants performed grammatical judgment throughout. No significant activation associated with grammatical status was found. This result is in contrast with research performed by P. J. Reber et al. (1998a, 1998b), in which participants viewed dot patterns that were members of a concept (each was a distortion of a prototypical pattern) and then decided whether novel stimuli were concept members or not. They found occipital (BA 18) activation to be greater for random stimuli than for concept members. In the present study, nongrammatical letter strings were similar to grammatical strings; it is likely that the differences that did exist were not large enough to cause significantly different neural processing or occurred in areas that were not imaged. Furthermore, the blocked nature of the test list, in which blocks of 12 grammatical strings alternated with blocks of 12 nongrammatical strings, differed from the usual artificial grammar task, in which grammatical and nongrammatical strings are randomly ordered. This structure may have affected the strategies used by participants and, by extension, brain activity.

The frontal and parietal areas activated for judgments have been associated with working memory (Smith \& Jonides, 1997) and reasoning tasks (Prabhakaran, Rypma, \& Gabrieli, in press; Prabhakaran, Smith, Desmond, Glover, \& Gabrieli, 1997). Thus, grammatical judgment and recognition may draw on the resources of working memory. Fletcher et al. (1999) found that frontoparietal networks were active in an artificial grammar task. Other concept-learning tasks have found frontoparietal activity, including a weather prediction task in which outcomes (rain or shine) were probabilistically related to visual cues (Poldrack, Prabhakaran, Seger, \& Gabrieli, 1999), a visual concept-learning task in which participants learned to differentiate visual stimuli as members of two categories (Seger et al., 2000), and a rule-based classification task (Smith, Patalano, \& Jonides, 1998).

The two cerebral hemispheres may play different roles in the development of categorical expertise: The right hemisphere specializes in processing specific stimuli, whereas the left hemisphere specializes in processing patterns abstracted across stimuli (Goldberg \& Costa, 1981). Behavioral research indicates that the right hemisphere performs memory judgments about specific vi- sual items more quickly and accurately than does the left hemisphere (Marsolek, Squire, Kosslyn, \& Lulenski, 1994; Metcalfe, Funnell, \& Gazzaniga, 1995). The finding of right frontal activity in recognition is consistent with these results. Conversely, the left hemisphere performs judgments about prototypical examples of a visual concept more rapidly than does the right hemisphere (Marsolek, 1995). The finding of left frontal activity in grammatical judgment is consistent with the left hemisphere superiority for abstraction.

\section{REFERENCES}

Altmann, G. T. M., Dienes, Z., \& Goode, A. (1995). Modality independence of implicitly learned grammatical knowledge. Journal of $E x$ perimental Psychology: Learning, Memory, \& Cognition, 21, 899-912.

BERRY, D. C., \& DiENES, Z. (1993). Implicit learning: Theoretical and practical issues. Hillsdale, NJ: Erlbaum.

Bradshaw, J., \& NetTleton, N. (1983). Human cerebral asymmetry. Englewood Cliffs, NJ: Prentice-Hall.

Buckner, R. L., Koutstaal, W., Schacter, D. L., Dale, A. M. Rotte, M., \& Rosen, B. R. (1998). Functional-anatomic study of episodic retrieval: II. Selective averaging of event-related fMRI trials to test the retrieval success hypothesis. Neumlmage, 7, 163-175.

Buckner, R. L., Koutstaal, W., Schacter, D. L., Wagner, A. D., \& ROSEN, B. R. (1998). Functional-anatomic study of episodic retrieval using fMRI. Neurolmage, 7, 151-162.

Cohen, N. J., Poldrack, R. A., \& Eichenbaum, H. (1997). Memory for items and memory for relations in the procedural/declarative memory framework. Memory, 5, 131-178.

CORKIN, S. (1968). Acquisition of motor skill after bilateral medial temporal-lobe excision. Neuropsychologia, 6, 255-265.

Dienes, Z., AltmanN, G. T. M., \& Gao, S.-J. (1999). Mapping across domains without feedback: A neural network model of transfer of implicit knowledge. Cognitive Science, 23, 53-82.

Dolan, R. J., \& FletCHER, P. F. (1999). Encoding and retrieval in the human medial temporal lobes: An empirical investigation using functional magnetic resonance imaging. Hippocampus, 9, 25-34.

Fletcher, P., Buchel, C., Josephs, O., Friston, K., \& Dolan, R. (1999). Learning-related neuronal responses in prefrontal cortex studied with functional neuroimaging. Cerebral Cortex, 9, 168-178.

Fletcher, P., Shallice, T., Frith, C. D., Frackowiak, R. S. J., \& Dol.AN, R. J. (1996). Brain activity during memory retrieval: The influence of imagery and semantic cueing. Brain, 119, 1587-1596.

Fletcher, P., Shallice, T., Frith, C. D., Frackowiak, R. S. J., \& DolaN, R. (1998). The functional roles of prefrontal cortex in episodic memory: II. Retrieval. Brain, 121, 1249-1256.

Friston, K. J., Frith, C. D., Turner, R. D., \& Frackowiak, R. S. J. (1995). Characterizing evoked hemodynamics with fMRI. NeuroImage, 2, 157-165.

Friston, K. J., Holmes, A. P., Worsley, K. J., Poline, J. P., Frith, C. D., \& FraCKowiaK, R. S. J. (1995). Statistical parametric maps in functional imaging: A general linear approach. Human Brain Mapping, 2, 189-210.

GoldberG, E., \& Costa, L. D. (1981). Hemisphere differences in the acquisition and use of descriptive systems. Brain \& Language, 14, 144-173.

Gomez, R. L. (1997). Transfer and complexity in artificial grammar learning. Cognitive Psychology, 33, 154-207.

Gomez, R. L., \& SCHVANEveldT, R. W. (1994). What is learned from artificial grammars? Transfer tests of simple association. Journal of Experimental Psychology: Learning, Memory, \& Cognition, 20, 392-410.

Graf, P., SQuire, L. R., \& Mandler, G. (1984). The information that amnesic patients do not forget. Journal of Experimental Psychology: Learning, Memory, \& Cognition, 10, 164-178. 
Henson, R. N. A., Rugg, M. D., Shallice, T., Josephs, O., \& Dolan, R. J. (1999). Recollection and familiarity in recognition memory: An event-related functional magnetic resonance imaging study. Journal of Neuroscience, 19, 3962-3972.

KNOWLTON, B. J., Ramus, S. J., \& SQuire, L. R. (1992). Intact artificial grammar learning in amnesia: Dissociation of classification learning and explicit memory for specific instances. Psychological Science, 3 , 172-179.

KNOWLTON, B. J., \& SQuire, L. R. (1994). The information acquired in artificial grammar learning. Journal of Experimental Psychology: Learning, Memory, \& Cognition, 20, 79-91.

KNOWLTON, B. J., \& SQuiRE, L. R. (1996). Artificial grammar learning depends on implicit acquisition of both abstract and exemplarspecific information. Journal of Experimental Psychology: Learning, Memory, \& Cognition, 22, 169-181.

Knowlton, B. J., Squire, L. R., Paulsen, J. S., Swerdlow, N. R., Swenson, M., \& ButTers, N. (1996). Dissociations within nondeclarative memory in Huntington's disease. Neuropsychology, 10, 538-548

Krause, B. J., Schmidt, D., Mottaghy, F. M., Taylor, J., Halsband, U., Herzog, H., Tellmann, L., \& Muller-Gartner, H.-W. (1999). Episodic retrieval activates the precuneus irrespective of the imagery content of work pair associates: A PET study. Brain, 122, 255-263.

Macleod, A. K., Buckner, R. L., Miezin, F. M., Petersen, S. E., \& RAICHLE, M. E. (1998). Right anterior prefrontal cortex activation during semantic monitoring and working memory. Neurolmage, 7, 41-48.

ManZA, L., \& Reber, A. S. (1997). Representing artificial grammars: Transfer across stimulus forms and modalities. In D. Berry (Ed.), How implicit is implicit learning? (pp. 73-106). Oxford: Oxford University Press.

MARSOLEK, C. J. (1995). Abstract visual-form representations in the left cerebral hemisphere. Journal of Experimental Psychology: Human Perception \& Performance, 21, 375-386.

Marsolek, C. J., Squire, L. R., Kosslyn, S. M., \& Lulenski, M. E. (1994). Form-specific explicit and implicit memory in the right cerebral hemisphere. Neuropsychology, 8, 588-597.

Mathews. R. C., Buss, R. R., Stanley, W. B., Blanchard-Fields, F. Cho, J. R., \& Druhan, B. (1989). Role of implicit and explicit processes in learning from examples: A synergistic effect. Journal of Experimental Psychology: Learning. Memory, \& Cognition, 15, 1083-1100.

Metcalfe, J., Funnell, M., \& Gazzaniga, M. S. (1995). Righthemisphere memory superiority: Studies of a split-brain patient. $P s y-$ chological Science, 6, 157-164.

NisSEN, M. J., \& BulLEMER, P. (1987). Attentional requirements of learning: Evidence from performance measures. Cognitive Psychology, $19,1-32$

Nolde, S. F., Johnson, M. K., \& Raye, C. L. (1998). The role of prefrontal cortex during tests of episodic memory. Trends in Cognitive Sciences, 2, 399-406.

Nyberg, L., Cabeza, R., \& Tulving, E. (1996). PET studies of encoding and retrieval: The HERA model. Psychonomic Bulletin \& Review, 3, 135-148.

Petersen, S. E., Fox, P. T., Snyder, A. Z., \& Raichle, M. E. (1990) Activation of extrastriate and frontal cortical areas by visual words and word-like stimuli. Science, 249, 1041-1044.

Poldrack, R. A., Prabhakaran, V., Seger, C. A., \& Gabrieli, J. D. E. (1999). Striatal activation during cognitive skill learning. Neuropsychology, 13, 564-574.

Prabhakaran, V., Rypma, B., \& Gabrieli, J. D. E. (in press). Neural substrates of mathematical reasoning: An fMRI study of neocortical activation during performance of the necessary arithmetic operations test. Neuropsychology.

Prabhakaran, V., Smith, J. A. L., Desmond, J. E., Glover, G. H., \& GABRIELI, J. D. E. (1997). Neural substrates of fluid reasoning: An fMRI study of neocortical activation during performance of the Raven's Progressive Matrices test. Cognitive Psychology, 33, 43-63.
Price, C. J., Wise, R. J. S. Watson, J. D. G, Patterson, K., HowARD, D., \& FrackowiaK, R. S. J. (1994). Brain activity during reading: The effects of exposure duration and task. Brain, 117, 1255-1269.

Puce, A., Allison, T., Asgari, M., Gore, J. C., \& McCarthy, G. (1996). Differential sensitivity of human visual cortex to faces, letterstrings, and textures: A functional magnetic resonance imaging study. Journal of Neuroscience, 16, 5205-5215.

Pugh, K. R., Shaywitz, B. A., Shaywitz, S. E., Constable, R. T. Skudlarski, P., Fulbright, R. K., Bronen, R. A., Shankweiler, D. P., Katz, L., Fletcher, J. M., \& Gore, J. C. (1996). Cerebral organization of component processes in reading. Brain, 119, 1221-1238.

REBER, A. S. (1967). Implicit learning of artificial grammars. Journal of Verbal Learning \& Verbal Behavior, 6, 855-863.

REBER, A. S. (1969). Transfer of syntactic structure in synthetic languages. Journal of Experimental Psychology, 81, 115-119.

REBER, A. S. (1989). Implicit learning and tacit knowledge. Journal of Experimental Psychology: General, 118, 219-235.

Reber, P. J., Stark, C. E. L., \& SQuire, L. R. (1998a). Contrasting cortical activity associated with category memory and recognition. Learning \& Memory, 5, 420-428.

Reber. P. J., Stark, C. E. L., \& Squire, L. R. (1998b). Cortical areas supporting category learning identified using functional MRI. Proceedings of the National Academy of Sciences, 95, 747-750.

Rugg, M. D., Fletcher, P. C., Allan, K., Frith, C. D., Frackowiak, R. S. J., \& DOLAN, R. J. (1998). Neural correlates of memory retrieval during recognition memory and cued recall. Neurolmage, 8, 262-273.

Rugg, M. D., Fletcher, P. C., Frith, C. D., Frackowiak, R. S., \& DOLAN, R. J. (1996). Differential activation of the prefrontal cortex in successful and unsuccessful memory retrieval. Brain, 119, 2073-2083.

Schacter, D. L., Buckner, R. L., Koutstaal, W., Dale, A. M., \& RosEN, B. R. (1997). Late onset of anterior prefrontal activity during true and false recognition: An event-related $\mathrm{fMRI}$ study. NeuroImage, 6, 259-269.

SEgER, C. A. (1994). Implicit learning. Psychological Bulletin, 115, 163-196.

SEGER, C. A. (1998). Independent judgment-linked and motor-linked mechanisms in artificial grammar learning. Consciousness \& Cognition, 7, 259-284.

Seger, C. A., Poldrack, R. A., Prabhakaran, V., Zhao, Z., Glover, G., \& GABRIELI, J. D. E. (2000). Hemispheric asymmetries and individual differences in visual concept learning as measured by functional MRI. Neuropsychologia, 38, 1316-1324.

Shulman, G. L., Corbetta, M., Buckner, R. L., Raichle, M. E., Fiez, J. A., Miezin, F. M., \& Petersen, S. E. (1997). Top-down modulation of early sensory cortex. Cerebral Cortex, 7, 193-206.

Shulman, G. L., Fiez, J. A., Corbetta, M., Buckner, R. L., Miezin, F. M., Raichle, M. E., \& Petersen, S. E. (1997). Common blood flow changes across visual tasks: II. Decreases in cerebral cortex. Journal of Cognitive Neuroscience, 9, 648-663.

SMITH, E. E., \& JoNidEs, J. (1997). Working memory: A view from neuroimaging. Cognitive Psychology, 33, 5-42.

Smith, E. E., Patalano, A. L., \& Jonides, J. (1998). Alternative strategies of categorization. Cognition, 65, 167-196.

SQUIRE, L. R. (1994). Declarative and nondeclarative memory: Multiple brain systems supporting learning and memory. In D. L. Schacter \& E. Tulving (Eds.), Memory systems 1994 (pp. 203-232). Cambridge, MA: MIT Press.

Squire, L. R., Ojemann, J. G., Miesin, F. M., Petersen, S. E., Videen, T. O., \& Raichle, M. E. (1992). Activation of the hippocampus in normal humans: A functional anatomical study of memory. Proceedings of the National Academy of Sciences, 89, 1837-1841.

Talairach, J., \& Tournoux, P. (1988). Co-planar stereotactic atlas of the human brain. New York: Thieme.

Tulving, E., Kapur, S., Craik, F. I. M., Moscovitch, M., \& Houle, S. (1994). Hemispheric encoding/retrieval asymmetry in episodic memory: Positron emission tomography findings. Proceedings of the $\mathrm{Na}$ tional Academy of Sciences, 91, 2016-2020.

Uchida, I., Kikyo, H., Nakajima, K., Konishi, S., Sekihara, K., \& 
Mryashita, Y. (1999). Activation of lateral extrastriate areas during orthographic processing of Japanese characters studied with fMRI. Neurolmage, 9, 208-215.

Wagner, A. D., Desmond, J. E., Glover, G. H., \& Gabrieli, J. D. E. (1997). Prefrontal cortex and recognition memory: Functional-MRI evidence for context-dependent retrieval processes. Brain, 121, 1985-2002.

Warrington, E. K., \& Weiskrantz, L. (1970). The amnesic syndrome: Consolidation or retrieval? Nature, 228, 628-630.

Wharton, C. M., Grafman, J., Filename, S. K., Hansen, E. K.,
Brainier, J., Marks, A., \& Honda, M. (1999). The neuroanatomy of analogical reasoning. Manuscript submitted for publication.

Woods, R. P., Cherry, S. R., \& Mazziota, J. C. (1992). Rapid automated algorithm for aligning and reslicing PET images. Journal of Computer Assisted Tomography, 16, 620-633.

(Manuscript received July 19, 1999; revision accepted for publication November 22, 1999.) 